\title{
Optimization of the Excavator-and-Dump Truck Complex at Open Pit Mines - the Case Study
}

\author{
Nuray Demirel ${ }^{1}$, Amir Taghizadeh ${ }^{1}$, Samer Khouri $^{2}$, and Ekaterina Tyuleneva ${ }^{3, *}$ \\ ${ }^{1}$ Mining Engineering Department, Middle East Technical University, Üniversiteler Mah., Dumlupınar \\ Bulvarı, No: 1, 06800 Çankaya, Ankara, Turkey \\ ${ }^{2}$ Technical University of Kosice, Faculty of Mining, Ecology, Process Control and Geotechnologies, \\ Letná 9, 04200 Kosice, Slovak republic. \\ ${ }^{3}$ T.F. Gorbachev Kuzbass State Technical University, Surveying and Geology Department, 650000 \\ Kemerovo, 28 Vesennya st., Russian Federation
}

\begin{abstract}
The transition to the use of the new equipment requires a revision of previously established dependencies, which constitute the methodological basis for optimization to ensure the highly efficient operation of technological equipment of the excavator-and-dump truck complex that performs all technological processes of overburden. The imperfection of the existing methods of optimization is due to the use, as a rule, of empirical formulas for the obsolete equipment installed to calculate the performance, so replacing or partially adjusting these dependencies, including methods and tools for determining process parameters, is an urgent task. Therefore, it is important to establish the parameters of each of the conjugate technological processes for the development of hard rock and half-rock overburden, which together provide the optimal results of the entire excavator-and-dump truck complex. The article considers the use of excavator-and-dump truck complex optimization as a criterion for the average weighted size of pieces of exploded rock mass, which allows determining the optimal parameters of each of the associated technological processes, their costs, as well as the total costs of the technology as a whole.
\end{abstract}

\section{Introduction}

To ensure the efficient operation of excavators of large unit capacity (with a bucket with a capacity of more than $40 \mathrm{~m}^{3}$ ), it is necessary to monitor the quality of the blasted rock mass preparation throughout the shotpile section, which can be realized by the joint use of reference and actual photoplanograms supplemented by direct timekeeping observations of the excavation process.

The goal of optimization is to choose the best from the possible solutions according to the accepted criterion under specific conditions. The best option is the one in which the necessary process conditions are met during the planned period, and the function value

\footnotetext{
* Corresponding author: tyulenevaea@kuzstu.ru
} 
reaches an extremum, i.e. the highest productivity at given costs or the current productivity with minimum expenses. Optimization primarily comes down to choosing process parameters that minimize unit costs, but they provide the necessary requirements for product quality [1-2]. In this regard, the optimization of the excavator-and-dump truck complex parameters of the open pit consists in determining the minimum of the total specific costs of overburden excavation for the entire technology and the parameters of each of the processes for the technical means used, taking into account the physical and mechanical properties of the rocks being developed, which ensure optimal operating conditions [3-5]. The main idea is that by constructing the graphical dependence of the change in the unit cost of stripping for each process of the applied technology (drilling and blasting, excavation, transportation and dumping) on the weighted average size of the piece of the blasted overburden, when summing these costs, a minimum zone of total costs can be defined. On the other hand, the value excavator-and-dump truck e of the weighted average size of the lasted rock piece determines the parameters of each of the processes for the technical means used, taking into account the physical and mechanical properties of the rocks being dev excavator-and-dump truck eloped, which ensure optimal operating conditions for the entire excavator-and-dump truck complex [6-7].

\section{Materials and Methods}

On the Tuva open pit of the Siberian Coal Energy Company (SUEK), Russian Federation, the Bucyrus-495HD excavator is used to develop overburden for dump trucks. It is equipped with a trapezoid-shaped bucket with a capacity of $41.3 \mathrm{~m}^{3}$ (Fig. 1).

The loading of the rock is carried out in the BelAZ-75306 dump trucks with the carrying capacity of 220 tons. Developed rocks are represented by sandstones with interlayers of siltstones and coal, requiring preliminary loosening using drilling and blasting. Some rocks $(\approx 30 \%)$ belong to the category of "medium explosive rocks" - these are mudstones, siltstones and sandstones on clay and carbonate cement with a large fracture (their density is 2.2-2.4 t $/ \mathrm{m}^{3}$ ); coefficient of strength according to Protodyakonov $f=6-10$; the value of natural separation $D=1.5 \mathrm{~m}$. Some rocks $(\approx 70 \%)$ belong to the "hard rock" category - mudstones, siltstones and fine-grained sandstones on carbonate and siliceous cement, large-block $r=2.4-2.8 \mathrm{t} / \mathrm{m}^{3}$; with Protodjakonov $f=8-12$; the value of the natural separation is $1.8 \mathrm{~m}$.

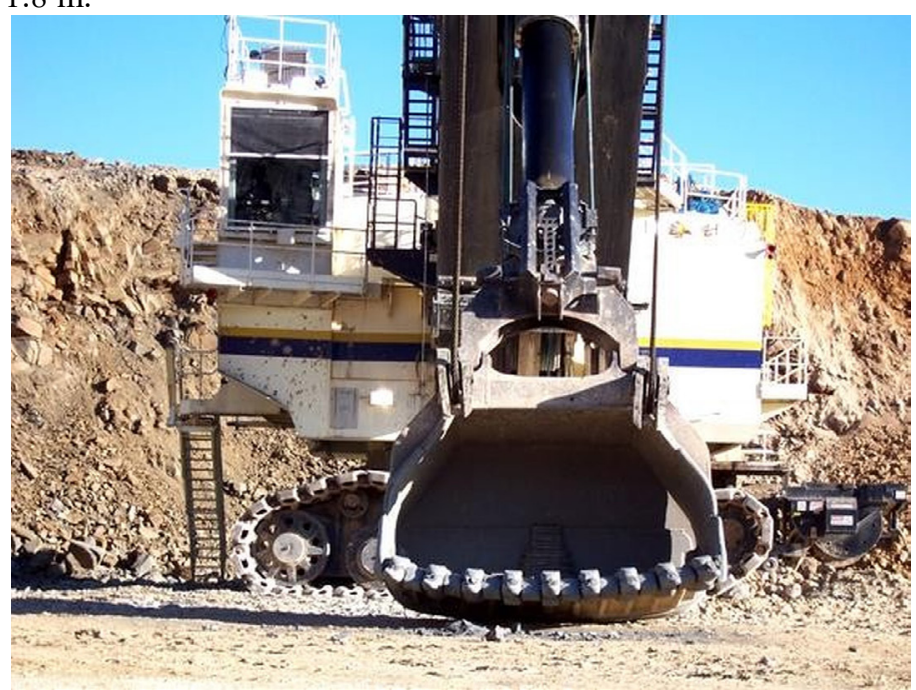

Fig. 1. The shape of the Bucyrus $495 \mathrm{HD}$ excavator bucket. 
Overburden operations on the Tuva open pit are almost completely performed using drilling and blasting work. As the initial geological information for drilling and blasting design, the data from geological exploration wells is used, which are often even outside the blast block. It is assumed that the geological structure presented by this data is uniform for the whole block, and this is far from real geological conditions of overburden development, because the rock mass being developed has a complex structure, the location of hard and weak rock layers is constantly changing and it is almost impossible to predict the location of hard layers in depth. The project of drilling and blasting works based on the such data often leads to uneven crushing of the rock mass, a large number of oversized rock pieces. In some cases, it is necessary to re-blast a part of the block.

In the initial period of operation of this excavator on Tuva open pit mine in December 2015 , the average daily productivity of the excavator was 36.5 thousand $\mathrm{m}^{3}$. Daily monitoring and chronometer observation using the working time in a shift allowed identifying a number of technical-and-organizational changes including loading dump trucks into two standings (Fig. 2) and a constant work of wheel dozer in the face to provide an entrance and parking plan for loading dump truck, which allowed to bring the daily output up to 55 thousand $\mathrm{m}^{3}$.

It was established that with a qualitatively carried out drilling and blasting preparation of the rocks to the excavation, the height of the bench not less than $15 \mathrm{~m}$ and the angle of rotation of the excavator when loading up to $70^{\circ}$, its working cycle time was $35-40 \mathrm{sec}$.

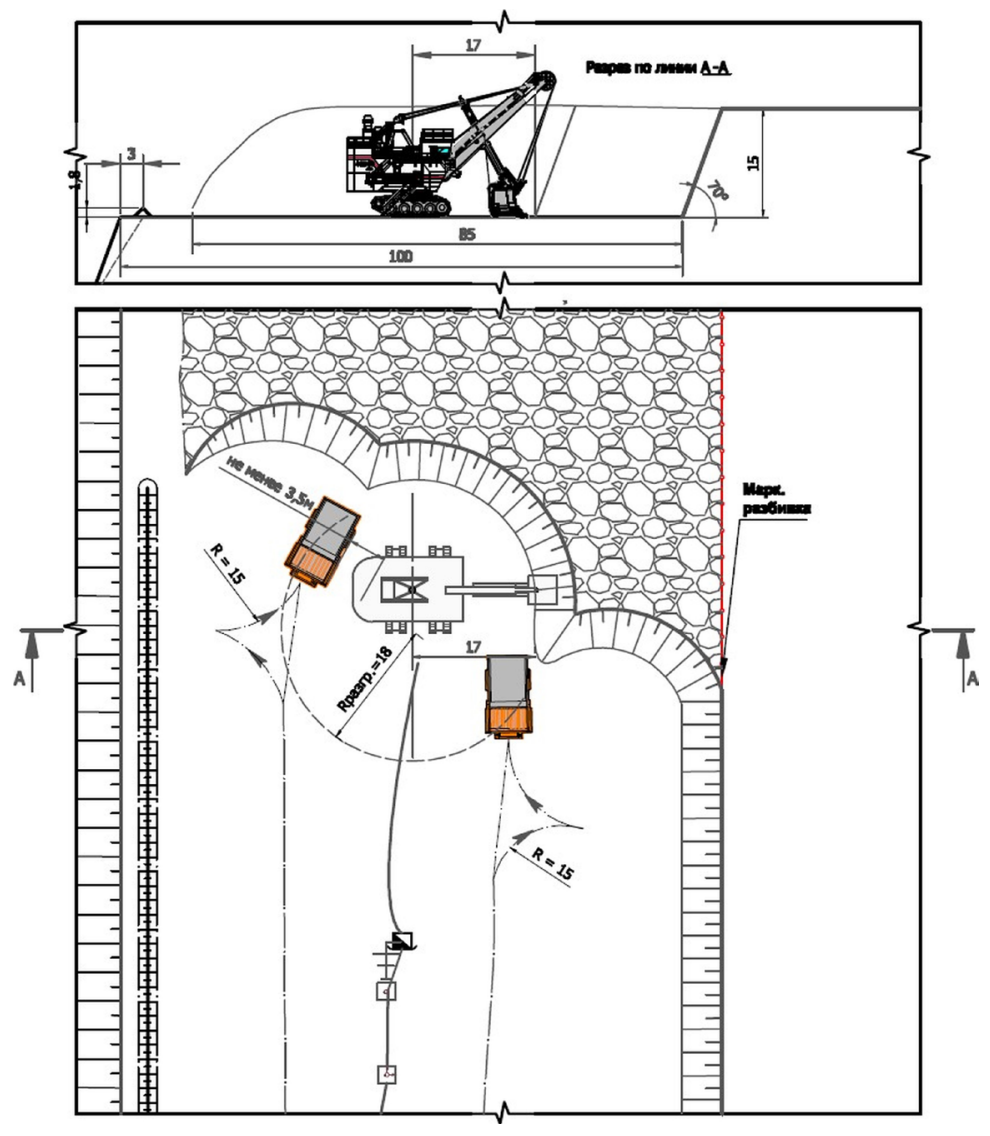

Fig. 2. The work of Bucyrus-495HD for loading BelAZ-7530 dump trucks in two standings. 
Analysis of the use of intra-shift time revealed reserves to improve the excavator's usage, the main of which is to reduce the waiting time for dump trucks and maneuvers of the excavator in the face.

Analysis of the expenditure of the calendar time during the year showed that as a result of the implementation of the technical policy adopted at the Tuva open pit mine, the excavator's technical availability and utilization rates were fairly high.

\section{Results and Discussion}

Studies have shown that the parameter characterizing the entire aggregate of fractions, the granulometric composition of the blasted rocks and determining the technological parameters of drilling and blasting work and, consequently, the costs of this process is the value of the weighted average size of pieces of blasted overburden (Das).

The intensification of mining operations in quarries is usually achieved using excavating equipment of large unit capacity, in particular, the well-proven excavator Busyrus-HD495. In this regard, it is expedient to estimate the possible operational productivity of the excavator used in the quarry taking into account the quality of the explosive crushing of the rock mass. Such a calculation of the operational capacity differs from the results according to conventional methods and is more in line with the operating conditions of the equipment. For the excavation process, the granulometric composition of the rocks being developed is also decisive. The productivity of the excavator depends on the lumpiness of the blasted rocks, or, more accurately, the value of the excavation factor and the time taken to pick up the bucket (with a sufficient height of the bench), and the productivity determines the cost of the process.

One of the methods for controlling lumpiness is short-delayed blasting. This kind of blasting is described as the alternating explosion of charges or a group of explosives with such small decelerations in response time at which residual tension and emerging additional exposed surfaces caused by an explosion of a previous charge (or a group of charges) can be used. The short-delayed blasting is applied for the following purposes:

- reducing the seismic effect of the explosion;

- improving the degree of crushing of the rock mass and reducing the output of the oversize;

- increasing in the yield of rock mass from a unit of the length of the well and reducing the debit of explosives;

- decreasing the width, changing the direction or shape of the shotpile of blasted rock mass; - reducing the size of zones of macrocracks and microcracks, as well as increasing the angle of the slope of the ledge;

- ensuring the good workout of the resistance on the bottom of the bench in case of a multiple-row arrangement of well charges.

Improving the crushing of rocks by the short-delayed blasting is achieved by prolonging the period of the explosion on the array, the formation of additional open surfaces, the collision of rocks during the explosion and the less unresolved rear part of the array in comparison with the instantaneous blasting.

Sandwiched blasting is the method of blasting, wherein due to the presence of barriers (blasted rock mass or pillar) the lateral displacement of blasted array decreases during destruction which increases the duration of action of the explosion on the array and, consequently, improves the rock crushing. Effectiveness of the method of sandwiched blasting occurs only when there are multiple short-delayed blasting and there are at least four or five rows of wells. However, in all variants, due to the retaining wall and a lower 
displacement speed and the duration of the explosion, the utilization factor of the blast energy raises. This is the physical nature of sandwich blasting.

Furthermore, based on the condition that the intensity of rock crushing by explosion along with the tension, the duration of explosive pulse action affects the rock, the effect of height bench (charge column length) on basic physical factors of rock destruction by explosion (the dependence of the duration of the blast pulse from the height of the bench) was studied. Advantages of blasting high (combined) benches are the following:

- providing large reserves of blasted rock mass with a lack of working berms;

- reducing in the volume of drilling operations due to the reduction of re-drills;

- reducing the consumption of detonating material;

- reducing of the drilling rig moves from well to well;

- increasing the productivity of loading and transport equipment for excavating blasted rock mass.

Additional drilling and blasting works efficiency can be achieved by using parallel-andproximity charges. This is explained by the fact that in this blasting method, in close proximity of charges at distances that are about $1 / 2$ of the distance between charges in a pair, the cylindrical fronts of the stress wave of the first and second charges begin to interact, forming a flat front. In order to increase the energy of well charges, especially for high-quality crushing and working out at the plantar part of high benches, a method of parallel-close blasting by well charges can be introduced. The essence of the method is as follows.

The drilling of the blasted bench is performed by groups of several vertical or inclined wells located in parallel to each other at a distance of six charge diameters from each other. There are parallel-and-proximity charges in one line (pairwise close) or in the form of a bundle of three (at the vertices of an equilateral triangle) and more wells (square, ellipse and other forms). A beam or a pair of parallel-close charges is oriented parallel to the line of the bench. Thus, an equivalent explosive charge of a large diameter is formed, which increases the efficiency of blasting operations. With the transition to this method of blasting it appears possible with the limited choice of diameters of charges $(215,250,270 \mathrm{~mm})$ form with the existing drilling rigs in the enterprise to make parallel connivent well charges that imitate the charge with required diameter and explosive energy.

One of the modern methods of control of the rock crushing quality by blast is tamping. The main purposes of tamping are the following:

- prevents chemical losses during detonation of industrial explosives;

- contributes to the completeness of detonation and releases the maximum share of the potential energy of industrial explosives;

- controls the geometric size of the shotpile of the blasted rock mass;

- reduces the yield of oversized pieces of blown rock;

- controls the crushing of rocks along the height of the bench;

- reduces the shock-air wave formed under the action of detonation wave of explosive charges;

- increases the energy efficiency of the explosion;

- increases the size of zones of rock array weakening;

- helps reducing the amount of toxic gases in the products of the explosion.

The length of the tamping should be such that leakage through cracks in the walls of the well does not exceed the leakage through the block. Further increase in the length of the tamping is not advisable, because does not affect the improvement of crushing, since the main leakage occurs through the walls of the well. As the upper part of the bench turns out to be far from the charge and is poorly crushed, the length of the tamping must be taken such that the amount of leakage of the explosion products through the block does not exceed the leakage through the walls of the wells. 
When choosing the type of explosive, it is necessary to take into account the physical and mechanical properties of rocks, watering the faces and the necessary mechanization of the wells's charging. The use of explosives from the existing assortment most fully meets the requirement of expanding the explosive pulse action during the explosion of a single charge and regulating the volumetric energy concentration of explosives

One of the modern methods for regulating the crushing of rocks by an explosion is the charge design and shape, which has a significant influence on the duration of the explosive pulse in the array. It has been proved by the papers that in the case of dispersed charge application with an air gap the locking of the detonation products of the main charge occurs. This leads to an extension of the explosion to the array. At present, charge structures with air gaps between charges, and between charge and breakdown can be widely recommended. Charge dispersal and application of truncated wells allowed reducing the breakdown of rock mass, to increase the yield of conditioning fractions $0-700 \mathrm{~mm}$ by 8 $10 \%$, reduce the oversize output from 18 to $8-10 \%$, reduce the average diameter of the piece and thereby increase the degree of crushing by $30-32 \%$. The increase in the degree of crushing made it possible to increase the productivity of crushers and excavators by 20 $25 \%$ and to reduce the cost of secondary crushing by $30 \%$. At present, the blasting of rocks by inclined well charges is widely used in open pit mining.

To calculate the average size of a piece in the breakdown of rocks the following formula has been developed and proposed. It makes it possible to establish the dependence of the change in the weighted average size of a piece on the specific consumption of explosives in certain mining and geological conditions of a quarry.

$$
D_{a v}=\frac{K \times D_{j i}^{0.61} \times f^{0.2} \times \Delta^{0.25}}{Q^{0.75} \times q}
$$

where $K$ - dimensional coefficient, which depends on the strength of rocks, can be calculated by the expression $\mathrm{K}=3+0,7 f$ and has the dimension $\mathrm{kJ} / \mathrm{kg} ; D_{b l}-$ average block size in the rock array, $\mathrm{m} ; f$ - the rock hardness coefficient by Protodjakonov; $\Delta$ charge density, $\mathrm{kg} / \mathrm{m}^{3} ; Q$ - the heat of explosion (energy), $\mathrm{kJ} / \mathrm{kg} ; q$ - specific consumption of explosive, $\mathrm{kg} / \mathrm{m}^{3}$.

The quality of the blasted rock mass in dumping process is indirectly affected, depending on the performance of the excavator and dump trucks, because this processes determine the amount of rock that fits in the dump. The economic costs of the process are determined in accordance with the productivity of the excavator-and-dump truck complex, adopted by the technology of dumping and the technical means used at the enterprise (bulldozers, etc.).

\section{Conclusion}

In considered conditions, the productivity of dump trucks depends more on the organizations of excavating and loading operations, and the quality of the blown rock mass is affected by changing the loading time of the dump truck. The lumpiness of the blasted rocks first affects the time of picking the bucket, the degree of congestion of the dump truck and, as a consequence, determines its fuel consumption. At the same time, the degree of loading of the dump truck does not directly depend on the lumpiness of the rocks, but is determined during loading. 


\section{References}

1. T. Gvozdkova, S. Markov, N. Demirel, S. Anyona, E3S Web of Conferences 21, 01024 (2017)

2. M. A. Tyulenev, S. A. Zhironkin, O. I. Litvin, E. A. Tyuleneva, O. V. Zhironkina, S. O. Markov, Geotechnical and Geological Engineering, 35:5, 2065-2077 (2017)

3. V. Golik, Yu. Dmitrak, E3S Web Conf., 21, 01018 (2017)

4. M. Tyulenev, O. Litvin, M. Cehlár, S. Zhironkin, M. Gasanov, Acta Montanistica Slovaca, 22:3, 296-302 (2017)

5. S. Zhironkin, M. Gasanov, G. Barysheva, K. Kolotov, O. Zhironkina, E3S Web of Conferences, 15, 03012 (2017)

6. V. Golik, Yu. Dmitrak, E3S Web Conf., 21, 01025 (2017)

7. A. B. Efremenkov, A. A. Khoreshok, S. A. Zhironkin, A. V. Myaskov, IOP Conference Series: Earth and Environmental Science, 50:1,012009 (2017) 